\title{
"This land was Mexican once/ Was Indian always/ and is./ And will be again". El papel de la memoria colectiva en la formación del discurso feminista chicano
}

\author{
"This land was Mexican once/ Was Indian always/ and is. / \\ And will be again". The role of the collective memory \\ in forming the Chicano feminist discourse
}

\author{
Anna Skonecka \\ Uniwersytet im. Adama Mickiewicza w Poznaniu, Instytut Filologii Romańskiej \\ Zakład Literatury Hiszpańskiej i Iberoamerykańskiej \\ anna.skonecka@amu.edu.pl
}

\begin{abstract}
The purpose of this article is to analyze the theoretical discourse of the Chicano feminists in order to determine the role of the collective memory in forming that discourse. The subject of the analysis will be mainly the mandatory reference to the postcolonial feminisms, namely the masterpiece by Gloria Anzaldúa and Cherríe Moraga titled Esta puente mi espalda. Voces de mujeres tercermundistas en los Estados Unidos. However, in order to present a complete overview of the Chicano discourse, we will also mention the work of scholars like Sonia Saldívar-Hull, Ana Castillo and Emma Pérez.
\end{abstract}

Keywords: Chicana feminism, collective memory, the United States, Mexico, borderlands

\section{HABLAN LAS BLANQUEADAS, ENCALLADAS Y ENOJADAS: EL CONTEXTO DE LA FORMACIÓN DEL FEMINISMO CHICANO}

La franja fronteriza mexicano-estadounidense constituye un espacio poscolonial problemático, cuya complejidad histórica y política le hace desaparecer del discurso hegemónico estadounidense. El cambio forzado de la frontera geopolítica entre México y Estados Unidos en el año 1848 ocasionó el surgimiento de la cultura chicana: desde el momento de su aparición, sus representantes se ven obligados a nego- 
ciar su estatus en el híbrido espacio mexicano-estadounidense. La conciencia de un traumático pasado común resulta ser la clave para la formación de la identidad chicana: la memoria colectiva común se convierte de esa manera en uno de sus principales agentes definitorios. El fenómeno de la colonización se realza también en las estructuras del feminismo formado en esta región: durante muchos años, las experiencias y traumas de las mujeres de color seguían ensordecidas por la voz del feminismo occidental blanco. El feminismo chicano, surgido en los años 70 de manera casi paralela al movimiento chicano, forma parte de una propuesta política más amplia, con la cual las feministas de color tratan de recuperar su voz marginada: con el fin de hacerlo, desarrollan un discurso propio, enfocado en la interseccionalidad de la discriminación experimentada. El motivo principal que aumentó la solidaridad entre las mujeres chicanas fue su gran decepción tanto por los postulados del movimiento feminista como por el feminismo canónico de Occidente; por otra parte, la creciente actividad política de las alternativas ramas del feminismo, inspiradas entre otras por la Colectiva del Río Combahee, incitó a las chicanas a formular sus propios postulados. De todo lo dicho se desprende que el feminismo chicano es un movimiento complejo, cuya forma actual se debe a diferentes formas de opresión sufridas por sus fundadoras por tales cuestiones como el género, la raza o la clase.

El objetivo del presente artículo es llevar a cabo un análisis del discurso teórico de las feministas chicanas con el fin de resaltar cuál es el papel de la memoria colectiva en la formación del dicho pensamiento. Para entender bien sus postulados, es de suma importancia evocar los factores más significativos que incitaron a las feministas a alzar la voz: la primera referencia obligatoria constituye, pues, el grupo étnicocultural del que proviene el discurso aquí analizado. Aunque en un principio el concepto del chicano hacía referencia únicamente a los mexicano-americanos y los inmigrantes mexicanos implicados en el movimiento chicano, con el paso de tiempo ha recobrado un significado más amplio: como apunta la socióloga polaca, Anna Kaganiec-Kamienska (2008), hoy en día este término abarca a las personas involucradas en cualquier actividad cultural, social o política que utilizan este término para autoidentificarse. Asimismo, es de suma importancia destacar que la particularidad de los chicanos no reside tanto en su origen y raíces, sino en su diferencia cultural, ocasionada por las interacciones de la cultura nativa con la cultura mexicana en los intersticios del Primer y Tercer Mundo. Así pues, el movimiento chicano de los años 60 y 70 fue un punto clave para la formación de la conciencia chicana: su objetivo consistía en crear un grupo propio, un tercer espacio idiosincrático en vez de negociar su identidad entre las categorías étnicas ya existentes. Como apunta otra vez Kaganiec-Kamienska, "aunque tales elementos como la lengua, la religión o la tradición (la herencia de los antepasados mexicanos y aztecas) son muy importantes, se hace el hincapié en los símbolos colectivos y culturales contemporáneos" (2008, p. 99). Uno de los principales símbolos de la cultura chicana aprovechado tanto por los participantes del movimiento como por las feministas chicanas constituye 
Aztlán, es decir, la tierra mítica desde la que vinieron los aztecas para fundar México. De acuerdo con lo destacado por Luis Leal, el símbolo de Aztlán adquiere su importancia actual en la Conferencia de Denver en el 1969; de hecho, queda mencionado por primera vez en "El Plan Espiritual de Aztlán”, con el fin de resaltar los orígenes aztecas de los chicanos (Anaya, 1998, p. 11). Aztlán recobra el doble significado haciendo la referencia a la región cedida por México por las decisiones del Tratado de Guadalupe Hidalgo por una parte; por otra, ha de manifestar la unión espiritual de los chicanos al evocar sus antecedentes comunes. Cabe destacar que el mismo concepto aparece en el primer título de la obra Borderlands/ La Frontera de Gloria Anzaldúa, "The homeland, Aztlán”, en el cual la escritora también alude a los orígenes de la cultura chicana.

A pesar de compartir ciertas cuestiones fundamentales para la identidad, tales como la conciencia histórica, los orígenes y los símbolos, las feministas chicanas discrepan con los fundadores del movimiento chicano en su modo de dividir los roles de género; como explican, el movimiento surgió a base de las reglas patriarcales, que trataban de mantener a las mujeres en estado de continua inferioridad. Dicho de otro modo, las feministas chicanas reprochan a los representantes del movimiento chicano que, por muy revolucionarios que fueran sus postulados, no son capaces de romper con la dicotomía de los roles femeninos, arraigados desde el siglo XVI, en la primera conquista de México. Como destaca Aída Hurtado (2003), igual que hacía cuatro siglos, durante el movimiento las mujeres aún seguían divididas en las categorías de marianismo y malinchismo: de acuerdo con esta distinción, el papel de las llamadas "buenas mujeres" las limitaba al rol de amas de casa, inscritas al ámbito doméstico. Al rebelarse contra la evidente discriminación de género, las mujeres fueron acusadas de traicionar todos los fundamentos de la cultura chicana; como destaca otra vez la investigadora:

Cuando las feministas cuestionaron su papel en el Movimiento Chicano, fueron percibidas por ambos, hombres y mujeres, como si no solo hubieran atacado las prácticas desiguales de género sino como si también hubieran cuestionado los fundamentos católicos de toda cultura chicana. En consecuencia, la emergente conciencia chicana feminista fue percibida como una traición y las feministas chicanas fueron tachadas de anti-familia, anti-cultural, anti-hombre y, por lo tanto, anti-movimiento chicano. (Hurtado, 2003, p. 16; traducción propia)

Frente a la discriminación masculina proveniente del movimiento chicano, las mujeres han buscado el apoyo en el discurso de sus aliadas femeninas de Occidente; no obstante, han reconocido con amargura que aún a finales del siglo XX y a principios del siglo XXI las reivindicaciones del feminismo hegemónico, cuyos postulados han revisado, siguen correspondiendo más a los problemas de las bien acomodadas mujeres blancas, descritos por Betty Friedan ya en el año 1963, que a la discriminación a la que están sometidas hoy en día las representantes del Tercer Mundo. En su 
caso, a diferencia de lo proclamado por el feminismo blanco, el género nunca es el único determinante de la opresión en la franja fronteriza mexicano-estadounidense: no obstante, tales categorías como la raza, la clase y la sexualidad, esenciales para su condición de inferioridad, no ganan suficiente importancia en el discurso canónico de Occidente. El carácter elitista del feminismo blanco impide a las mujeres de color identificarse con sus postulados; frente a esta exclusión, Gloria Anzaldúa concluye de manera tajante:

No es probable ser amigas de gente literaria en lugares altos, la principiante de color es invisible en el mundo principal del hombre blanco y en el mundo feminista de las mujeres blancas, aunque en este hay cambios graduales. La lesbiana de color no solo es invisible, ni siquiera existe. Nuestro lenguaje, también es inaudible. Hablamos en lenguas como las repudiadas y locas. (1998, p. 220)

El análisis crítico del feminismo blanco hace a Sonia Saldívar-Hull cuestionar sus elementos constitutivos, tales como la universalidad del altisonante concepto de la sororidad; como advierte la investigadora:

Si extendemos la analogía al feminismo y al concepto totalizador de la sororidad, empezamos a entender cómo los intereses específicos de las feministas anglo-americanas y otras feministas europeas tienden a borrar la existencia de la feminista chicana, puertorriqueña, la nativa americana, la asio-americana y otras feministas tercermun0 distas. De hecho, la manera en la que se practica el feminismo por las mujeres de la cultura hegemónica oprime y explota a la chicana tanto de manera sutil como evidente. (2000, p. 37; trad. propia)

Finalmente, inspiradas por la Colectiva Río Combahee y otras iniciativas tercermundistas, a finales de los años 70 las feministas chicanas decidieron alzar la voz, oponiéndose a que la imagen de la mujer equivaliera únicamente a la de la mujer blanca. Como aseguran las autoras Gloria Anzaldúa y Cherríe Moraga (1998), su obra titulada Esta puente mi espalda. Voces de mujeres tercermundistas en los Estados Unidos, publicada en el año 1981, constituye la respuesta a la falta de cualquier movimiento viable de las feministas de color en los Estados Unidos. Como alternativa al carácter elitista del feminismo blanco aparece la visión de un feminismo poscolonial, capaz de abarcar a las mujeres-víctimas de todo el tipo de opresión, ignorada por el discurso hegemónico. La envergadura de este movimiento, conocido también en términos de "feminismo tercermundista", queda explicado por Gloria Anzaldúa de la siguiente manera:

La visión del feminismo radical tercermundista hace como una necesidad nuestro empeño en trabajar con esa gente que se siente cómoda en el mundo zurdo - las marginalidades de este mundo: los de color, los jotos, los pobres, la hembra, los incapacitados-. De nuestra conexión de sangre y espíritu con estos grupos, nosotras mujeres de abajo a través del mundo podemos formar un feminismo internacional. Juntas podemos formar 
una visión que alcanza desde el autoamor de nuestras pieles de color hasta el respeto de nuestras madres antepasadas [...]. (Anzaldúa \& Moraga, 1998, p. 152)

El hecho de que el discurso de las chicanas pueda inscribirse dentro del movimiento cuya premisa principal, de acuerdo con lo destacado por Ewa Domańska, es que "las consecuencias coloniales se convierten en una de las principales injusticias sociales, al lado de las condicionadas por los constructos de la clase, el sexo y la raza" (Domańska, 2008, cit. por Nowicka, 2010), determina de manera considerable el carácter de los recuerdos evocados en sus obras. La memoria colectiva se convierte en la categoría que une la experiencia de las mujeres chicanas oprimidas por la cultura hegemónica blanca, abarcando cualquier tipo de la discriminación que surge de su condición colonial. Gracias al conocimiento del contexto socio-histórico en el que se forma el discurso feminista chicano, podremos reconocer cada uno de los particulares niveles de la colonización a la que están sometidas sus autoras. Reconocer la intereseccionalidad de la discriminación chicana significa entender la multiplicidad de los tipos de opresión a la que están continuamente expuestas las mujeres de color en los Estados Unidos. Teniendo en cuenta todo lo dicho anteriormente, no es de extrañar el empeño de las feministas chicanas en la tarea de formular una voz que hable por todas ellas; una tarea en la que la memoria colectiva juega un papel principal.

\section{2. "LA HISTORIA ME FUE DENEGADA,}

\section{LA LENGUA DE MI ABUELA ARRANCADA DE MI BOCA": LA MEMORIA COLECTIVA EN EL CONTEXTO CHICANO}

La fecha de 2 de febrero de 1848 marca un antes y un después tanto en la vida de las habitantes de los territorios conquistados por los Estados Unidos como en su escritura, estrechamente vinculada a sus experiencias vitales. El dolor relacionado con la particular pérdida de la patria queda transmitido en su discurso, cuya mejor muestra constituye el poema de Gloria Anzaldúa titulado "No se raje, chicanita:

Y sí, nos han quitado las tierras.

Ya no nos queda ni el camposanto

donde enterraron a Don Urbano, tu vis-visabuelo [sic].

Tiempos duros como pastura las cargamos

derechitas caminamos.

Pero nunca nos quitarán ese orgullo

de ser mexicana-Chicana-tejana

ni el espíritu indio.

Y cuando los gringos se acaban

- mira como [sic] se matan unos a los otros-

aquí vamos a parecer [sic]. (2007, pp. 222-223) 
El poema de Ángela de Hoyos, titulado "Hermano" y publicado en el año 1975 transmite la misma amarga tristeza: "Nací demasiado tarde / en una tierra / que ya no me pertenece/ (por lo que dice aquí, en la historia de Texas) [...] / Nací demasiado tarde / o quizás nací demasiado pronto / todavía no es mi tiempo; todavía no es mi casa" (Saldívar-Hull, 2000, p. 17).

Los dos fragmentos, junto con la cita utilizada en el título del presente artículo, constituyen unos ejemplos de la profusa presencia de las alusiones directas a las consecuencias geográficas del Tratado de Guadalupe Hidalgo en el discurso feminista chicano. Cabe destacar, no obstante, que la mayoría de las experiencias evocadas por las activistas dan cuenta de las repercusiones psicológicas y los trastornos de la identidad provocadas por su condición colonizada. El cambio de la frontera geopolítica destruye por completo el sentimiento de la seguridad de los habitantes de la tierra conquistada, causando confusión en las que son demasiado jóvenes para entender lo que está pasando; como apunta Sonia Saldívar-Hull: "He aprendido de mis padres que Matamoros, y por extensión el resto de México, no era mi «casa»; sin embargo, como niña crucé (la frontera) casi cada fin de semana con mis abuelos Treviño" (2000, p. 3). Aída Hurtado, por su parte, destaca la importancia de revisar la narrativa oficial referente a los acontecimientos históricos relacionados con la colonización de México. La investigadora hace hincapié en los drásticos cambios de la vida cotidiana que se vieron obligados a afrontar los habitantes del espacio recién colonizado; a pesar de su gran envergadura, es una cuestión ignorada por el discurso histórico oficial. Como explica Hurtado:

De la noche a la mañana, la gente residente en lo que se había convertido en el suroeste de los Estados Unidos, tenía un nuevo gobierno que impuso un idioma diferente, una cultura diferente y un orden político diferente [...]. La historia de la colonización afecta a todos los descendientes mexicanos, independientemente de si eran la parte del territorio conquistado o no. México, como nación aún siente la pérdida de su pasado. Gran parte del Southwest lleva signos de haber pertenecido a México: los nombres de las ciudades y de las calles, la presencia de las misas católicas y de los edificios históricos y las vibrantes prácticas culturales que siguen vivas. (2003, p. 14)

La imposición de la cultura americana, junto con todas sus secuelas correspondientes, ha dejado una huella considerable en la identidad de las feministas chicanas: su discurso retoma la forma del testimonio de una nación blanqueada y acallada, a la que se privó de sus constructos culturales más significativos. A pesar del paso de tiempo, las habitantes de la comunidad conquistada llevan sus traumas a flor de piel; Cherríe Moraga evoca las relaciones del poder, fundadas a base del color de la piel:

Nunca nadie me dijo precisamente que lo claro fuera lo correcto, pero yo sabía que ser de color claro era algo que se valoraba particularmente en mi familia (toda chicana, a excepción de mi padre). De hecho, todo lo que tuvo que ver con mi educación (al menos la que ocurrió a nivel consciente), trato de blanquear aun más el color que yo tenía [...]. 
Mi madre puede recordar todo esto como si fuera ayer. Pero es algo que quiere olvidar (y con derecho), pues para ella, ser chicano significa en un nivel económico muy elemental ser "menos". Y fue por ese deseo intenso de mi madre de proteger a sus hijos de la pobreza y del analfabetismo, que nos "anglizamos". Cuanto más efectivamente pudiéramos pasar por el mundo blanco, más garantizado estaría nuestro futuro. (Anzaldúa \& Moraga, 1998, p. 20)

Los recuerdos perpetuados por las escritoras en sus obras retoman formas variadas: la rabia, entremezclada con una interminable tristeza queda expresada a través de los poemas o en prosa, con unas palabras muy tajantes o envueltas en la sutileza de las metáforas. No obstante, detrás de todas esas páginas hay un objetivo común: conservar la memoria de una comunidad que después de casi dos siglos sigue estando oprimida y acallada. Efectivamente, todos los textos anteriormente mencionados cumplen con su tarea: cada una de las experiencias singulares invocadas por las feministas chicanas contribuye a la formación de un fenómeno considerablemente más amplio, es decir, la memoria colectiva chicana. Aunque parezca poco lógico entrelazar estos dos aparentemente opuestos fenómenos, como lo son la memoria individual y la memoria colectiva, los estudios del sociólogo francés, Maurice Halbwachs, demuestran lo contrario. Así pues, por un lado, la definición misma de los recuerdos particulares conlleva un matiz de subjetividad; de acuerdo con lo subrayado por Ricoeur: "mis recuerdos no son los vuestros. En cuanto mía la memoria es un modelo de lo propio, de posesión privada" (Ricœur, 2003, cit. por MéndezReyes, 2008). No obstante, el factor que permite leer los recuerdos particulares en un contexto más amplio es su articulación social. Como argumenta Halbwachs:

Cada memoria individual es un punto de vista sobre la memoria colectiva, que este punto de vista cambia según el lugar que yo ocupo, y que este lugar mismo cambia según las relaciones que mantengo con otros medios. Porque son individuos que se acuerdan en cuanto son miembros de grupos. En este sentido, memoria individual y colectiva se relacionan. (2004, p. 50)

Otra cuestión analizada por Halbwachs que resulta ser clave para nuestro análisis constituye la distinción entre dos tipos de recuerdos que conforman la memoria colectiva: así pues, en sus estudios el sociólogo hace referencia a los recuerdos vividos (denominados también como autobiográficos) y los recuerdos históricos. En cuanto al primer grupo, su significado es bastante evidente, puesto que abarca "los recuerdos cuya fuente es la experiencia personal del sujeto sobre un determinado acontecimiento o período histórico" (Muller \& Bermejo, 2013, p. 250). Ahora bien, aunque es cierto que, en sus obras, las feministas chicanas se centran en su propia experiencia, describiendo las dificultades que supone formar un grupo cultural diferente al de la cultura hegemónica, en su discurso aparecen también las alusiones a lo que consideran como la fuente de su desgracia: el Tratado de Guada- 
lupe Hidalgo y los recuerdos desarrollados acerca de este acontecimiento se convierten en uno de los protagonistas principales de su escritura. De acuerdo con lo proclamado otra vez por Maurice Halbwachs (2004, p. 54), no es imprescindible ser un testigo directo de un suceso para poder clasificarlo en términos de nuestro propio recuerdo: la importancia de este recuerdo reside en su pertenencia al contexto del grupo del que formamos parte. El testimonio indirecto abarcado dentro de la categoría de los recuerdos históricos se convierte de este modo en el segundo elemento constitutivo de la memoria colectiva; este concepto está definido de la siguiente manera:

[Los recuerdos] se basan en los acontecimientos indirectos de un hecho o momento histórico, obtenidos, por ejemplo, a través de los libros de historia u otro tipo de archivos, y se mantienen vivos por medio de conmemoraciones y actos festivos. Si los recuerdos autobiográficos o vividos tienen como base a los individuos, los recuerdos históricos tienen como agente a las instituciones ya que son ellas las que almacenan e interpretan el pasado. (Muller \& Bermejo, 2013, p. 250)

El análisis del discurso feminista chicano demuestra claramente que sus autoras siguen sumergidas en el mismo contexto de la opresión poscolonial de la que daban cuenta sus antepasadas. El hecho de que varias generaciones de las mujeres chicanas contribuyan a la formación de una memoria colectiva común, basada en la misma condición de inferioridad frente a la cultura colonizadora, constituye un triste testimonio de la vigencia de la interseccionalidad de discriminación, sufrida por parte de las mujeres de color en la franja fronteriza mexicano-estadounidense.

\section{RECLAMANDO UN SITIO Y UNA LENGUA: LA (DES)COLONIZACIÓN DE LA MEMORIA CHICANA}

Todo lo anterior nos lleva a corroborar la presencia explícita del tema de la memoria colectiva en el discurso feminista chicano. El estatus específico de los chicanos, clasificados en términos de una comunidad doble conquistada, constituye uno de los hilos conductores de su escritura; una escritura que, a pesar de su gran capacidad expresiva, sigue siendo una literatura minoritaria con un público limitado. $\mathrm{Si}$ tomamos en cuenta las palabras de Halbwachs, según las cuales la mayor diferencia entre la memoria y la historia estriba en el hecho de que puede haber varias memorias colectivas mientras que la historia es solo una (2004, p. 84), nos damos cuenta no solo de la gran responsabilidad sino también del enorme privilegio del que tiene el derecho de construirla como la única versión oficial. Gloria Anzaldúa afirmó ya hace tiempo: "La cultura la hacen aquellos en el poder — hombres" (2007, p. 38)—. De manera paralela podemos admitir la hipótesis de que el derecho de escribir la historia está en las mismas manos. Aunque el esfuerzo y las luchas de las 
feministas blancas han contribuido a su inscripción, por muy escasa que sea, a la versión oficial de la historia, esta sigue siendo una historia blanqueada y colonizada. En consecuencia, la voz de las mujeres de color es un concepto que, por lo general, brilla por su ausencia en el discurso hegemónico occidental. En el contexto feminista más amplio, la memoria colectiva se convierte en una categoría fundamental que pone de manifiesto dicha colonialidad de la historia. Consiguientemente, en las páginas que siguen, trataremos de fijar el vínculo entre la lengua y la historia, apoyándonos en los estudios de Walter Mignolo y Emma Pérez. El fin último del presente trabajo es demostrar de qué manera las feministas chicanas recurren a la memoria colectiva común para descolonizar el discurso feminista vigente.

Las experiencias de las chicanas recopiladas en forma de sus obras, hacen comprobar lo acertado que son las palabras de Emma Pérez cuando esta afirma: "La lengua, después de todo, es el poder. La gente del Tercer Mundo sabe que aprender el idioma del colonizador da un acceso al poder y privilegio, aunque sea un poder controlado, cualificado" (1991, p. 165, trad. propia). Efectivamente, la opresión lingüística sufrida por las chicanas constituye uno de los recuerdos más contundentes y a la vez más traumáticos de su infancia: como reconocen con amargura, la interminable discriminación a la que se ven sometidas a lo largo de toda su vida, empieza con la prohibición del uso del español en el colegio. Mientras que Sonia Saldívar-Hull describe la supremacía de los que han logrado comunicarse en la lengua del colonizador, Gloria Anzaldúa evoca el sentimiento del rechazo el cual ha hecho a la comunidad chicana sentirse como "deslenguadas, los del español deficiente" (2007, p. 80); no obstante, es Emma Pérez la que refleja de manera más pertinente el estrecho vínculo entre el idioma y la memoria. Su comparación reveladora de la pérdida de lengua con la pérdida de memoria nos lleva a las reflexiones de Walter Mignolo (1998) acerca de la colonización de la memoria. Aunque en su artículo "La colonización del lenguaje y de la memoria: complicidades de la letra, el libro y la historia", el investigador argentino examina de qué manera la posesión de las lenguas indígenas y la imposición de la gramática castellana condujeron a la colonización del lenguaje y la historia en el contexto de la conquista de América, el significado de este estudio es trágicamente universal. Exactamente en la misma tierra, la historia repite tres siglos más tarde, con la única diferencia de la fuerza colonizadora. De este modo, las conclusiones de Mignolo nos servirán para dar a conocer la colonización de la memoria chicana en toda su complejidad histórica.

En su detallado estudio de la situación de lenguas amerindias, el investigador subraya la importancia de la escritura de las gramáticas y su introducción en las comunidades colonizadas con el fin de disminuir la repercusión de su tradición oral existente. Gracias a esta demanda, los únicos que podían escribir la historia fueron los que dominaban el idioma impuesto, es decir los colonizadores. Como apunta Mignolo: 
Cuando emergen situaciones como éstas en las cuales el acto de escribir la historia de una comunidad significa, al mismo tiempo, reprimir la voz de ella y la posibilidad de que sus miembros sean escuchados, presenciamos un ejemplo de colonización de géneros (o tipos) discursivos. Cuando se trata de los géneros destinados a conservar la memoria y transmitir el pasado, estamos frente a un buen ejemplo de la colonización de la memoria. (1988, p. 17)

Si bien este fenómeno constituye un elemento intrínseco de las conquistas que empiezan en el siglo XVI, cabe destacar que a largo plazo el Tratado de Guadalupe Hidalgo conlleva las mismas repercusiones: esta vez la opresión no concierne a la tradición oral indígena, sino al idioma español, un elemento intrínseco de la identidad chicana. Emma Pérez describe la evidente supremacía del inglés de la siguiente manera:

El idioma nos viene de arriba para infligirnos con la ideología occidental blanca. Hablamos de nuestra historia el uno al otro igual que nuestros antepasados usaban la tradición oral. Una tradición reducida al mínimo. Tenemos que escribir en inglés reeducado para legitimar nuestro trabajo. Tenemos que dominar la lengua del colonizador antes de que se lean nuestros estudios. Gringos y gringas censuran nuestra lengua real que a menudo nace de la rabia. La lengua del colonizador. (1991, pp. 175-176)

La censura que enfrenta la literatura chicana al tener que pasar por el filtro de la lengua dominadora supone uno de los pasos de la colonización de la memoria, que, según afirma otra vez Walter Mignolo, consiste "precisamente, en o bien ignorar la producción cultural e intelectual de las comunidades coloniales, o bien reconocerlas $\mathrm{y}$ aún valorarlas convirtiéndolas, al mismo tiempo, en objeto descrito y analizado por medio de los tipos discursivos empleados en la comunidad colonizadora" (1988, p. 18). La colonización de la historia es un procedimiento extremadamente peligroso y perjudicial: a largo plazo, impide la formación de la memoria colectiva, cuyo básico elemento constitutivo (y el que la distingue de la historia), como nos recuerda Maurice Halbwachs (2004, p. 81), es su continuidad y capacidad de conservar lo vivo del pasado. Inevitablemente, suprimir la historia de las chicanas equivale a colonizar su memoria.

Las premisas del feminismo chicano, destacadas en las páginas anteriores, hacen inscribirlo dentro del movimiento más amplio, denominado como "feminismo descolonial". Su objetivo principal, de acuerdo con lo afirmado por Breny Mendoza (2014):

consistirá precisamente en la superación de esta colonialidad del género y esta colonialidad del ser que deshumaniza y convierte a las mujeres de la colonia en presa no sólo de los hombres colonizadores, sino de los hombres colonizados. El feminismo descolonial sería un tipo del feminismo que forma parte de la resistencia que los colonizados vienen ejerciendo desde que se inició el proceso de deshumanización a partir de la colonialidad del poder y el género. $(2014$, p. 54$)$ 
Con el presente artículo hemos tratado de demostrar que una de las etapas imprescindibles en el camino de la descolonización de la experiencia chicana constituye, sin duda alguna, la recuperación y el reconocimiento de su historia femenina. Como destaca Emma Pérez (1991), el trabajo de las chicanas emerge de un sitio y una lengua arraigados en ambas: las palabras y el silencio de las mujeres tercermundistas, lejos tanto de la gente blanca como de los hombres de color. Como afirma por su parte Aída Hurtado "los términos un sitio y una lengua de Pérez, captan la esencia del proyecto feminista chicano. Ambas partes - el sitio y la lenguatienen diferentes capas de significado. Reclamar una lengua significa reclamar el idioma, la lengua y el discurso. Reclamar un sitio incluye el lugar histórico, la ubicación geográfica y el espacio filosófico" (2003, pp. 5-6). La recuperación de la lengua y el espacio de las feministas chicanas puede cumplirse tan solo al superar la hegemonía de la voz occidental blanca. Las voces de las feministas chicanas resuenan con unanimidad al reivindicar un espacio para la formación de su memoria colectiva: todas coinciden en afirmar con certeza que ha llegado el momento de que los colonizadores pronuncien las palabras acalladas durante más de un siglo. De esta manera, el tono concluyente de Elba Sánchez se convierte en la voz del pueblo, que no piensa callar ni un segundo más:

Me has querido muda

Desde la infancia

Ahora

Mi lengua

Ha mordido las palabras

Desafiando

Lo que ya no es aceptable. (cit. por Hurtado, 2003, p. 13) 


\section{BIBLIOGRAFÍA}

Anaya, R., Lomelí, F. (1989). Aztlán: Essays on the Chicano Homeland. Albuquerque: University of New Mexico Press.

Anzaldúa, G. (2007). Borderlands/La frontera. San Francisco: Aunt Late Books.

Anzaldúa, G. \& Moraga, Ch. (1998). Esta puente, mi espalda. Voces de mujeres tercermundistas en los Estados Unidos. San Francisco: Ism Press.

Friedan, B. (2009 [1963]). La mistica de la feminidad. Madrid: Cátedra.

Halbwachs, M. (2004). La memoria colectiva. Zaragoza: Prensas Universitarias de Zaragoza.

Hurtado, A. (2003). Voicing Chicana Feminisms. Young Women Speak Out on Sexuality and Identity. New York - London: New York University Press.

Kaganiec-Kamieńska, A. (2008). Tożsamość na pograniczu kultur. Meksykańska grupa etniczna w Stanach Zjednoczonych. Kraków: Universitas.

Méndez-Reyes, J. (2008). "Memoria individual y memoria colectiva: Paúl Ricœur". AGORA Trujillo, 22, 121-130.

Mendoza, B. (2014). Ensayos de crítica feminista en nuestra América. México D. F.: Editorial Herder.

Mignolo, W. (1988). "La colonización del lenguaje y de la memoria: complicidades de la letra, el libro y la historia (1)". Recogido en: https://es.scribd.com/doc/145432958/Mignolo-Walter-D-La-coloni zacion- del-lenguaje-y-de-la-memoria (4 agosto 2016).

Muller, B., Bermejo, F. (2013). "Las fuentes de la memoria colectiva: los recuerdos vividos e históricos”. Revista de Psicología, 31 (2), 247-264.

Nowicka, M. (2010). „Czy teoria postkolonialna jest kobieca? Narodziny, rozwój i zmierzch postkolonializmu”. Przeglad socjologiczny, 59 (3), 109-165.

Pérez, E. (1991). "Sexuality and Discourse: Notes from a Chicana Survivor". En C. Trujillo (Ed.), Chicana Lesbians. The Girls Our Mothers Warned Us About (pp. 159-184). Berkeley: Third Woman Press.

Ricœur, P. (2012). Pamięć, historia, zapomnienie. Kraków: Universitas.

Saldívar-Hull, S. (2000). Feminism on the Border. Chicana Gender Politics and Literature. London: University of California Presss. 